\title{
Qualitative analysis of European and Middle East intensive care unit nursing death rituals
}

\section{Abstract}

Background- Grieving and death rituals vary widely across cultures and often are influenced geographical regions, religions, local norms. Nursing rituals reflect forms of cultural behavior that assist in communicating traditional knowledge and practices. They help nurses maintain social order through cohesion and interaction.

Aim: Exploration of European and Middle Eastern intensive care nursing ceremonies and rituals surrounding care provided to patients after death has occurred. The key question researchers asked was "can you describe your practice of caring for a patient who has died".

Method: Prospective qualitative thematic analysis investigating nursing practice and rituals when caring for patients who have died in intensive care. The interviews were conducted face-to-face with nurses consenting to be interviewed for research purposes. During the interviews, researchers noted sentences and topics, which they later classified into categories and sub-categories. The interview settings were international and national conferences, workshops, meetings and seminars over a twoyear period. Thematic analysis was performed. This analysis allowed the researchers to understand and make sense of collective meanings and experiences of participants.

Findings: 23 interviews with critical care nurses from 16 countries in Europe and Middle East were conducted. Through reflective and meaningful analytical interpretation, two main themes (with subthemes) emerged: Sacredness and Dignity. More similarities than differences among the nurses' experiences were found. Rituals included, opening a window, lighting a candle, blessing the deceased, and bereaving with the family.

Conclusions: Post-death ritual reflect local guidelines regulating the handling of the deceased body, culturally approved expressions of mourning, and acts to perform at specific times following death. Nursing rituals expressed here demonstrated the dignity, which nurses show towards the deceased and relationships between deceased and bereaved.

Relevance to clinical practice: The investigators perceived nursing culture, beliefs, ceremonies and rituals surrounding caring for patients who have died to be creative, spiritual, meaningful and relevant for nurses

\section{Introduction}

Denzin (1974) defines ritual as 'a joint act, involving two or more persons that is frequently repeated in the lives of those members. It is endowed with special, often sacred meaning, 
and is focused around a set of clearly defined objects'. Rituals are an integral part of life in any society (Rando, 1985), although the form of ritual varies with culture.

Lobar et al. (2006) studied death of a loved one by European, Asian, Caribbean, Central American and South American families. Many commonalities were found across cultures and religions. A pervasive theme was that beliefs about the soul of the deceased lead families to perform rituals and ceremonies that foster passage to God, the 'light', or another life. The stronger their beliefs, the more dedicated the family is in performing rituals and ceremonies as dictated by their religion or culture.

Worldwide, both religious and non-religious groups have developed rituals to help provide structure and support to those who mourn and to mark the death of the deceased. Elements of post-death ritual may involve guidelines regulating the manner of handling the body and final disposal, culturally approved expressions of mourning, or acts to perform at specific times following the death. Such rituals honour the deceased as well as the relationship between the deceased and the bereaved (Castle et al., 2003). There may also be rituals to honour and remember the deceased in the months and years following the death. Science fails to answer all the problems of clinical nursing. Because of this, rituals are worth exploring. Nursing rituals do not replace science but coexist with it. Nursing rituals reflect forms of cultural behaviour that assist in communicating traditional knowledge and practices. They help nurses maintain social order through cohesion and interaction (Suominen et al., 1997). Rituals in nursing demonstrate nurses' commitment to patients and families and to one another (Wolf 2013).

\section{Background}

Nursing has a culture of practice that includes the essential components of empathy, humanity, and a code of ethical behaviour and caring (Watson, 2011). A culture contains sets of values, beliefs, and habits learned during socialization, which shape the worlds of ideas, perceptions, decisions and actions. Each caregiver carries his/her own set of cultural values into the caring interaction (Doswell and Erlen, 1998, Wros et al., 2004). Although nurses' professional work is representative of the global nursing culture, some activities reflect unique values and traditions rooted in nurses' original culture (Rassin, 2008). 
Endacott et al. (2016) studied nurses' perceptions of end-of-life care in the UK and Israel. Although major differences exist in the medico-legal framework and extent of public and political involvement surrounding end-of-life issues in the two countries, such as the extent of religious involvement in dilemmas arising from care, nursing perceptions were found to be very similar. Despite clear differences in the legal context for dying in the two countries, nurses in the UK and Israel identified similar factors that they perceive to prevent, or contribute to, a good death and good quality of end-of-life care. Very little was found in the literature on the question of nurses' ceremonies and cultural practices surrounding death. Engler et al. (2004) illustrated neonatal nurses' perceptions of grief and end-of-life care of families of critically ill and/or dying infants. Although this study included the nurses' role, comfort and involvement with bereavement/end-of-life issues, the findings only noted that 'providing culturally sensitive bereavement/end-of-life care was an issue of some discomfort for all respondents' without including details of how nurses provide such care. In summary, grieving and death rituals vary widely across cultures and are often heavily influenced by religion (Lobar, 2006). The literature suggests many similarities across cultures, but also some important differences. In addition, nursing as a culture has its own regional as well as personal cultural uniqueness.

\section{Aim and objective of the study and research question}

The purpose of this study was to describe European and Middle Eastern intensive care nursing ceremonies and rituals surrounding care provided to patients after death has occurred. The key question researchers asked nurses was: "Can you describe to me your practice of caring for a patient who has died"? The investigators perceived nursing culture, beliefs, ceremonies and rituals surrounding caring for patients who have died to be creative, spiritual, meaningful and relevant for nurses.

\section{Design and methods}

This study used a prospective qualitative thematic analysis investigating nursing practice in ceremonies and rituals when caring for patients who have died in intensive care. The primary qualitative question was addressed to nurses individually: 'Can you describe your nursing practice and rituals when you care for patients who have died?' The investigators wrote participants' replies verbatim. Usually no further probing or questioning occurred. The 
investigators originate from different countries and upon meeting at an international conference in Norway they decided to interview ICU nurses from other countries as well as their own, and a study protocol was developed. The interviews were conducted face-to-face and the nurses gave their written consent with their initials to be interviewed for research purposes. Nurse research participants were recruited in the home countries of the investigators, during international conferences, and during investigator visits to countries for international meetings. During the interviews, the researchers noted sentences and topics, which they later classified into themes and sub-themes. Participants' names and IDs were not recorded, only the person's gender, hospital level of the ICU and the country. The interview settings were international and national conferences, workshops, meetings and seminars over a two-year period. Data were collected until saturation was reached. Thematic analysis was performed. This type of analysis allowed the researchers to see, understand and make sense of the collective meanings and experiences of participating nurses (Braun et al., 2014). Having created and applied a set of themes and concepts at the data management stage, the data were then meshed to organize descriptive accounts, detecting key concepts and synthesizing the mixture, range and variety of each narrative phenomenon. Eventually themes and subthemes were developed (see Table 2), at which stage the explanations were built and the data took form.

\section{Ethical and research approvals}

The study was conducted according to the principles of the Declaration of Helsinki (World Medical Association Declaration of Helsinki, 2013). The study does not fall under the provisions of the Act on Medical and Health Research in Norwegian legislation, since it does not generate new knowledge about health and disease or use human biological material.

Table 1: Participants' origin

\section{Findings}

This study is based on twenty-three interviews with female and male critical care nurses from 16 countries in Europe and the Middle East (Table 1). Through reflective and meaningful analytical interpretation, two main themes (Sacredness and Dignity) and five 
subthemes emerged (Table 2). We found more similarities than differences among the nurses' experiences. A few participants referred to ICUs that have written guidelines for endof-life care and for the process of dying. Most of the other participating nurses proudly told how care of the dying in the ICU was a 'craft' that was transferred to new nurses in an old nursing care tradition.

\section{Sacredness}

Personal rituals: Uniquely their own

More than half of the participants described how they performed individual unique rituals during the patients' last hours and after death. They had seldom discussed this practice with their colleagues, nor told the dead patients' family. Despite this, they talked very willingly about these rituals in the interviews. Although the nurses believed their rituals were personal and unique, we found similarities in the rituals for dying or after death across many of the participants' ICU practices, countries and religions.

One ritual was blessing the dead persons' body by touching the forehead or chest. Other nurses crossed themselves or the dead persons' body, or both. Some said a prayer or a poem in connection with the blessing.

A Swiss nurse said: 'After death I turn off the bed screen if I hadn't done it before. I wash and shave the dead patient, then I change the sheet. I wish him farewell and say he did well in his life'.

One nurse from Iceland found her practice as important for herself; however, she legitimized it most as an honour in respect and as a farewell. The significance of paying respect to the dying patient and the relatives was common across all participating nurses' ICUs. To care for a dying person was by most nurses never experienced as 'just a job', but was also emotionally demanding, and they sometimes had to 'leave the room just to cry'. The Icelandic nurse related: 'Personally, when all the care for the dead body is over, and before the family returns, I stay still bedside, and make the sign of the cross with the finger of my right hand over my chest, in respect and as a farewell to the dead person. We then light 
candles (nowadays these new electrical ones...) and place them on a tablecloth on the bedside table. We also bring in a hymn book, if the patient was a Christian.'

One nurse from an ICU in a Middle Eastern religious hospital had developed a 'palliative care cart' in her unit, containing a Bible, the Koran, amulet beads, a bottle of holy water, a book of hymns and prayers, CD music and head covering for the deceased. A similar arrangement was reported by a Norwegian nurse.

While a minority stated that they opened the window for fresh air and rejected performing any rituals, most participants reported opening a window to let the dead persons' soul fly or escape from this world and bid him or her farewell and a safe journey to 'the other side'. A nurse working in Germany narrated: 'I allow ample time for the relatives to say farewell, and I open the windows if possible'. If not hindered by cold or hot temperatures outside, they let the window remain open until the deceased was transferred to the mortuary. One of the nurses sadly said he was prevented in performing this ritual due to windows that could not be opened in their newly built ICU. He described it in this way: 'The old unit had a room with a window, but not this new one. It's been important for me to open the window to enable the soul to escape'.

In an Israeli ICU, the staff showed respect for the deceased by not eating or drinking until the person was transported to the mortuary.

\section{Dignity}

\section{Supporting the relatives}

Most study participants invited the dying patients' family in with few restrictions and they found it important to show the family respect and help them through this difficult life experience. This could imply leaving the relatives alone with the dying person if that was their wish. Other participants left them alone only after death had occurred.

Some described how they facilitated continued close contact between the relatives and the dying patient. As an example, they invited them to touch the patient and talk to him although he might be unconscious. An Italian nurse always tried to elicit family members' good experiences with the dying person and help them to bring out his or her significance in 
life. An Israeli nurse who encouraged the family members to tell stories about their life with the dying person and elicit powerful memories, used the same strategy:

'...as we saw the heart rate on the monitor slowly retreat from 40 to 30 to 20, I encouraged the son and daughter of RT to tell their father the most memorable events of their lives together. Immediately they both began speaking to their father and each one related different life incidents, remembering jokes and funny stories that their dad would retell during traditional family gatherings. The action of telling these stories riveted the children from a state of shock and immense distress to a situation of "doing", of saying an unforgettable farewell....'

A Norwegian nurse had in some situations, especially when the dying person was a child or young person, asked the mother or father to climb into the bed and lie close to the dying beloved person. She had experienced that most relatives were very grateful to be offered this opportunity for a final bodily contact as a farewell.

A German nurse preferred to leave the room if the family was comfortable to be alone with the dying person. From time to time, he went in to ask the family if they needed something. If the patient or the relatives wanted a ceremony arranged when the patient was still alive, most nurses took care of arranging such religious rituals by calling a clergyman, a priest or an imam, or brought in a hymn book or Bible for the family themselves to perform the ceremony or the blessings.

The participants were aware of relatives' need for precise and consistent information and to be guided and comforted through the dying process. Relatives often asked for an estimate of how long this process would take, which nurses found difficult to answer. When death was imminent, close family members could stay bedside as long as they wanted. However, one nurse from southern Europe described how some family members were asked to leave or wait outside if the relatives were too numerous. Some other participants had similar practices and seldom allowed more than two visitors at a time, unless the dying person had a single room. In most practices, however, relatives could stay with the patient when death finally occurred. One participant from Sweden said: 'They can come and go or stay as long as they want to'. Some nurses elicited relatives' own rituals and then arranged for those to be 
performed. In some ICUs, nurses asked the family to leave the room and wait outside when the patient died.

In general, nurses realized that beeping alarms would be frightening and disturbing, and therefore turned off the alarms on all technical devices, while others also turned off screens and infusion pumps.

Irrespective of whether the family was in the room or waiting outside, several nurses said that they needed to '.... create a dignified place to die versus a high-tech environment'. They removed unnecessary bedside technical equipment, or hid it behind screens, curtains or sheets.

A nurse working in France explains how they hurried to remove all technical and disturbing devices: 'When the patient is washed, all lines and instruments are removed. The patient is then wrapped in a sheet and only the head is uncovered for the family to touch. They can stay with the patient for at least two hours before the body is moved to the mortuary.'

We have interpreted this as an important gesture from the nurse towards the dying person's humanity. During the process of dying, the nurses described how they tried to maintain a calm and dignified atmosphere in the ICU. Noise was considered disturbing and disgraceful, especially in the dying patient's room. A symbol like a stone or an electric candle placed on a table in the corridor outside the room could be a signal to busy ICU staff to slow down and lower their voices.

We did not find an interprofessional approach to the families during the dying process. During the patient's last hours, nurses were mostly alone with the dying patient and the relatives. However, some stated that physicians visited the room to follow the process and to answer questions.

In northern Europe, some ICUs invited bereaved family members to an after-death follow-up conversation or sent a letter of condolence.

\section{Dignity during end-of-life and care for the dead patient}

If family members left the room during the moment of death or shortly thereafter, the nurses carefully washed the deceased's face and hands, provided a clean pillow and cover 
sheet and removed the most visible lines and tubes. A tablecloth covered the bedside table. Some lit a wax or battery-powered candle. A few practices involved premade silk flower decorations for the table or for the clean bedcover.

Then, with as little delay as possible, the family were invited in and comforted; nurses showed them respect by leaving them alone with the deceased if they preferred. Some ICUs offered relatives to participate in the bed bath of the deceased, or just to stay in the room when nurses performed this care. However, others asked the family members to wait outside and then return for a last farewell or a ceremony. A Swiss nurse preferred to wash the deceased alone as a tribute to the patient. However, most other nurses always gave the bed bath in pairs. Some ICUs had written guidelines for care of the dead body. Most others maintained proudly that they cared for the deceased in an old nursing tradition, with reference to an ethical practice, as one nurse said: '... We behave with the same respect to the deceased as if he or she was still alive'.

Almost all nurses practiced a universal procedure. They removed all tubes and lines and washed the whole body carefully. Some washed the hair as well. Males were shaved. During the care, the body was considered exactly as valuable as if the person was still alive. 'I need to do all I can to restore the humanity of the patient - this makes the patient a person once more, for us too.' They turned the body as if it still had senses and could have felt pain. They spoke in low voices. Interestingly, several said that they continued to talk to the deceased. As an example, some told the deceased what they were going to do next. Others said that their talk was different from when the patient was alive and was now adapted to the transition. Some commented on how the dead person finally was without suffering and seemed to be at peace. One Swiss nurse said: '.... I talk to the deceased and bid him farewell, wishing him a safe journey, asking him forgiveness and telling him he did good in this world'. A few nurses reported that they always let the dead body rest a while before they washed it, while most others performed the care within two hours. Relatives were sometimes asked if they wanted the body to be dressed in private clothes. Before the relatives left the ICU, they were provided with information about all practical details following a death.

After this, nurses placed an identification tag on the body's toe or chest, wrapped the body in sheets or put it into a body bag. The zipper was closed, but left open $10-20 \mathrm{~cm}$ just to avoid condensation. A sheet then covered the deceased before transport. A few ICUs had 
handcrafted bedcovers for re-use, some of which were patchwork in delicate colours. Several nurses reported choosing internal corridors with fewer people for the transport to the mortuary.

\section{Effectiveness}

While most nurses described the care in a humane and dignified way, others were businesslike, aiming at effectiveness and just considered after-death care as a job to 'get over and done with'. One nurse said: 'The next patient is always waiting'. She described a busy ICU where they never lit candles, offered ceremonies nor performed any other rituals.

\section{Interpersonal relationships and feelings for the deceased}

Many of the nurses talked about care for dying and dead persons as work that aroused feelings of sadness and sacredness. Being an experienced nurse helped them to handle death care better. Many spontaneously recalled how they felt afraid and insecure during their first experience with dying patients. None of the participants mentioned any follow-up services for nurses after the most demanding situations. They cope by talking it over with their colleagues to enable them to move on to the next situation.

Some commented that they found comfort in realizing that the deceased was now without suffering and seemed to be at peace. The death of a patient makes a difference: 'these people never leave you', as one nurse said. The participants often used the term 'we', which we have interpreted as a reference to a culture. No difference in this aspect was found among the participating nurses and countries.

Although most nurses considered rituals around death as their own unique practice, some acknowledged that they were passed from generation to generation of nurses: '.... it is my responsibility to pass this ritual art of nursing practice on to the next generation of nurses'.

Trustworthiness: This is a pilot study by three ICU nurses from Norway and Israel. The researchers were motivated by curiosity of seeking a broader perspective of end-of-life and after-death care. We addressed trustworthiness by attempting to achieve as broad a European and Middle Eastern sample as possible. By speaking with bedside nurses with a 
range of educational backgrounds and work experience, we believed we could capture a broad and in-depth perspective on nurses' practices in after-death care. We quickly achieved saturation of data, because we discovered that nurses describe much of the same creative, innovative, humane and spiritual after-death care. The themes and sub-themes were repeated regardless of the nurse's religion, country of origin, years of work experience or education. We therefore believe that the findings can be generalized to other ICU nurses.

\section{Discussion}

Nursing rituals continue to be performed as timeless acts to stabilize complexities of care. They remain the inner world of nursing. Rituals combine science and theory. The findings in our study correspond with those of Wolf (2013), who reports that rituals provide an inner world of private intimacy to the impersonal detached professional climate of birthing, health promotion, sickness and dying practices. Cunningham et al. (2019) report findings from a Delphi study exploring 'The Pause'. The Pause permits nurses to feel present and composed, provides a moment for reflection, and is a method to honour a deceased patient. Kapoor et al. (2018) performed a quantitative study demonstrating that the majority of ICU physicians and nurses participating in the study who practised a 'sacred pause' believed that the ritual brought closure and helped them overcome the feelings of disappointment, grief, distress and failure after the death of their patient in ICU. They also found that a majority agreed that the ritual had implanted a sense of team cohesion. In our study we did not name the moments of rituals as 'pauses'. However, like Kapoor et al. (2018), we found that when nurses were performing rituals, these moments were also significant in themselves. Interpersonal caring rituals function at a social level in the context of professional nursing. These rituals provide meaning for nurses, families and patients and establish order for their interactions and mutual experiences (Wolf, 2013).

Dossey and Keegan (2016, p. 141) emulate the work of Jean Watson and Florence Nightingale by integrating the concept of inner and outer environment and sacred space into their theory. They describe sacred space as 'a home for the spirit, providing rest, stillness, nature, and opportunities for opening to various connections'. In our study, we found that nursing death care was embedded in sacredness where the rituals marked the person's 
change and transition from one status to another. The rituals performed were at the same time perceived as nursing caring acts that upheld dignity during the transition. The nurse and anthropologist Hadders (2007) found in his study that the transition phase is considered as sacred and the body as being someone in between, as in a liminal status. This corresponds with our findings of nurses' respectful communication both directed to the deceased and to his or her soul by bidding the soul farewell while it moves on to another status.

Hadders (2008) says that nurses tend to individualize and domesticate clinical death and that they seek an authentic death, where individual routines and approaches are allowed. This complements our findings that nurses follow old nursing after-death care traditions but also show wide variation across countries and nursing cultures, allowing for more personalized care and ritual practices. We found that the rituals performed in our study were seldom witnessed by others, yet represented the nurse's personal values as well as the core values of professional nursing, thus reflecting the sacredness of the situation. The orientation of the rituals in caring for patients, families and fellow nurses is rooted in the essential ethical values of beneficence and respect for human dignity (Wolf, 2013). The findings demonstrate that nurses are motivated to perform many tasks and rituals that show respect and dignity for the patient who is no longer living. Nurses do, however, sometimes struggle when patients die. Similar to the findings of Wilson and Kirshbaum (2011), we found that the death of patients affects nurses, and nurses might need more education on grief theory and a better organized in-house follow-up service after the most demanding situations.

Symbols stand out in rituals; they are essential to ritual performance (Ball et al., 2013). They represent meanings that are not necessarily conscious and operate as a 'cognitive reflex' (Wolf, 2013). The ritual of washing the person is symbolic of 'flushing or rinsing the sickness and cause of death' to a new clean status, a pristine state to continue the journey (Ball et al., 2013).

Rituals communicate values and produce desired effects (Catanzaro, 2002). Our findings suggest that value of dignity and humanity in life as well as death is a cornerstone in nursing practice. In the high-tech critical care world, human dignity is not forgotten, and nurses are determined to keep this ethos strong and constant. Nurses need to sustain the power of their rituals to continue embracing the holistic paradigm. 


\section{Limitations}

As this was a qualitative study, the rituals, ceremonies and practices cannot be generalized to all nurses from all countries. Some of the participants stated that they did not perform any rituals. The methodology used to interview each participant was, however, uniform; the data analysis was performed primarily by one researcher and discussed with the other investigators. The researchers had few opportunities to meet to discuss this research, which was primarily conducted during international conferences and internet communication (emails, WhatsApp and Skype).

\section{Implications and recommendations for practice}

Our findings reflect that patients receive humane and respectful care not only in life also after death. Families can be comforted by knowing that their loved one receives not only upto-date intensive care technologies but also dignified spiritual care.

This study reflects creativity in nursing practice, merged with a sacredness of caring which crosses traditional cultural boundaries. Nurses reading this paper can adapt and introduce rituals acceptable to them, adding another dimension of caring into their practice. We recommend only adopting practices that feel ethically and practically appropriate to local nursing practice. The fine line between creativity and science and caring practice is individual, and must be synergized with local policies and accepted norms.

\section{WHAT IS KNOWN ABOUT THIS TOPIC}

- Most critical care units have after-death policies and procedures focusing on hygiene, cleansing and wrapping the body.

- The international literature discusses culturally sensitive, religious and dignified patient- and family-centred care during and after death.

- Critical care nurses have an essential role in the provision of effective end-of-life care; however, this dimension of their role needs further exploration.

\section{WHAT THIS PAPER ADDS}


- Provides insight into death rituals in critical care nursing

- Comparison of similarities from a pan-European and Middle Eastern perspective in after-death ICU nurse practices

- Using creativity to provide sacredness and dignity in after-death care, nurses can add a dimension to their practice for themselves and for the patients and their families

\section{Conclusion}

Worldwide, nurses have developed post-death rituals to help provide structure and support to those who mourn and to mark the death of the deceased. Elements of post-death rituals have reflected local guidelines regulating the manner of handling the body of the deceased and final disposal, culturally approved expressions of mourning, and acts to perform at specific times following the death. Nursing rituals expressed in this study demonstrated the dignity which nurses show towards the deceased as well as in relationships between the deceased and the bereaved. In addition to being aimed at the deceased and grieving families, many of these rituals were, importantly, also performed for the benefit of the nurse to enable the nurse to find meaning and sacredness for this final caring act.

\section{References}

Ball J, McGahee TW. (2013). Dedication of hands to nursing: A ceremony of caring. Journal of Nursing Education and Practice; 3(10): 58. https://doi.org/10.5430/inep.v3n10p58

Braun V, Clarke V. (2006). Using thematic analysis in psychology. Qualitative Research in Psychology; 3(2): 77-101. https://doi.org/10.1191/1478088706qp063oa

Castle J, Phillips WL. (2003). Grief rituals: Aspects that facilitate adjustment to bereavement. Journal of Loss \& Trauma; 8(1): 41-71. https://doi.org/10.1080/15325020305876

Catanzaro AM. (2002). Beyond the misapprehension of nursing rituals. Nursing Forum; 37(2): 17-27. https://doi.org/10.1111/j.1744-6198.2002.tb01194.x

Cunningham T, Ducar DM, Keim-Malpass J. (2019). "The Pause": A Delphi methodology examining an end-of-life practice. Western Journal of Nursing Research. https://doi.org/10.1177/0193945919826314

Denzin NK. (1974). The methodological implications of symbolic interactionism for the study of deviance. The British Journal of Sociology; 25(3): 269-282. https://doi.org/10.2307/589394

Dossey BM, Keegan L. (2016). Holistic nursing: A handbook for practice (7th ed.) Burlington, MA: Jones \& Bartlett Learning.

Doswell WM, Erlen JA. (1998). Multicultural issues and ethical concerns in the delivery of nursing care interventions. The Nursing Clinics of North America; 33(2): 353-361. 
Elo S, Kääriäinen M, Kanste O, Pölkki T, Utriainen K, Kyngäs H. (2014). Qualitative content analysis: A focus on trustworthiness. SAGE open; 4(1): 2158244014522633. https://doi.org/10.1177/2158244014522633

Endacott R, Boyer C, Benbenishty J,Ben Nunn M, Ryan H, Chamberlain W, Boulanger C, Ganz F D. (2016). Perceptions of a good death: A qualitative study in intensive care units in England and Israel. Intensive and Critical Care Nursing; 36, 8-16. https://doi.org/10.1016/i.iccn.2016.04.004

Engler A, Cusson R., Brockett T., Cannon-Heinrich C., Goldberg M, West M., Petow W., (2004). Neonatal staff and advanced practice nurses' perceptions of bereavement/end-of-life care of families of critically ill and/or dying infants. American Journal of Critical Care; 13(6): 489-498.

Hadders H. (2007). Dealing with the dead patient at the intensive care unit. Mortality; 12(3): 207-222. https://doi.org/10.1080/13576270701430726

Hadders $\mathrm{H}$. Handling death in the intensive care unit: medical practice and multiple ontologies. PhD Thesis. Trondheim. Norwegian University of Science and Technology. ISBN 978-82-471-1128-4

Kapoor S., Morgan K., Siddique A., Guntupalli K., (2018). "Sacred Pause" in the ICU: Evaluation of a Ritual and Intervention to Lower Distress and Burnout. American Journal of Hospice and Palliative Medicine; 35(10): 1337-1341. https://doi.org/10.1177/1049909118768247

Lobar SL, Youngblut JM, Brooten D. (2006). Cross-cultural beliefs, ceremonies, and rituals surrounding death of a loved one. Pediatric nursing, 32(1), 44-50.Lobar SL. et al. (2006). Cross-cultural beliefs, ceremonies, and rituals surrounding death of a loved one. Pediatric Nursing; 32(1): 44-50.

Rando TA. (1985). Bereaved parents: Particular difficulties, unique factors, and treatment issues. Social Work; 30(1): 19-23. https://www.jstor.org/stable/23714036

Rassin M. (2008). Nurses' professional and personal values. Nursing Ethics; 15(5): 614-630. https://doi.org/10.1177/0969733008092870

Suominen T, Kovasin M, Ketola O. (1997). Nursing culture-some view points. Journal of Advanced Nursin; 25(1): 186-190.https://doi.org/10.1046/i.13652648.1997.1997025186.x

Watson J. (2011). Nursing. Sebastopol: University Press of Colorado.

Wilson J, Kirshbaum M. (2011). Effects of patient death on nursing staff: a literature review. British Journal of Nursing; 20(9): 559-563. https://doi.org/10.12968/bjon.2011.20.9.559

World Medical Association Declaration of Helsinki: Ethical Principles for Medical Research Involving Human Subjects. JAMA. 2013; 310(20): 21912194, https://doi.org/10.1001/jama.2013.281053 
Wolf Z. (2013). Exploring rituals in nursing: joining art and science. Springer Publishing Company.

Wros P, Doutrich D, Izumi S. (2004). Ethical concerns: Comparison of values from two cultures. Nursing \& health sciences; 6(2): 131-140.

Wros PL. et al. (2004). Ethical concerns: Comparison of values from two cultures. Nursing and Health Sciences; 6(2): 131-140. https://doi.org/10.1111/i.1442-

$\underline{2018.2004 .00184 . x}$ 